\title{
BReast CAncer gene (BRCA): snapshot of the Middle East
}

\author{
Omalkhair Abulkhair ${ }^{1}$, Nagi S. El Saghir ${ }^{2}$ \\ ${ }^{1}$ Department of Oncology, Specialized Medical Center, Riyadh, Saudi Arabia; ${ }^{2}$ Division of Hematology-Oncology, Breast Center of Excellence, \\ American University of Beirut Medical Center, Beirut, Lebanon \\ Correspondence to: Omalkhair Abulkhair, MD. Department of Oncology, Specialized Medical Center, P.O. Box 66548, Riyadh 11586, Saudi Arabia. \\ Email: omal_danah@hotmail.com; omalkhair.abdullah@smc.com.sa.
}

Submitted Sep 11, 2019. Accepted for publication Feb 03, 2021.

doi: 10.21037/cco-19-204

View this article at: http://dx.doi.org/10.21037/cco-19-204

\section{Background}

Breast cancer (BC) is the most common cancer in the world, accounting for approximately $23 \%$ of all cancers that affect females worldwide, and remains the most common cause of mortality in women globally (1). About $5-10 \%$ of all BC cases (2) and more than $23 \%$ of all ovarian cancers (3) are thought to be hereditary. Hereditary breast and ovarian cancer is commonly caused by an autosomal dominant BReast CAncer gene (BRCA) germ line mutation which causes a higher than normal incidence of ovarian and $\mathrm{BC}$ in genetically related families (4).

Women in the Arab world are diagnosed with $\mathrm{BC}$ at more advanced stages, with the incidence rates in this region increasing over the last three decades (5-10).

\section{BRCA data}

BRCA gene mutations have been identified as the most commonly linked germ-line mutations (11). Pathogenic mutations in both $B R C A 1$ and $B R C A 2$ increase the risk of developing BC up to $85 \%$ and ovarian cancer up to $54 \%$ during woman's lifetime (12). BRCA mutation occurrences are known to differ between populations and ethnic groups. Some studies also describe significant differences in the spectrum of $B R C A 1$ compared with $B R C A 2$ mutations, and in the $B R C A 1 / 2$ variants of uncertain significance (VUS) $(13,14)$. For instance, from a sample of 46,276 women of non-Ashkenazi Jewish ancestry, females with African ancestry had the highest prevalence of VUS $[16.5 \%$ vs. $5.7 \%$ Western European; odds ratio (OR): 3.2, 2.8-3.7] (13), while $B R C A 2$ mutations were reported to be more frequent than those of BRCA1 in the Asian population (15). Furthermore, population-specific mutations have also been described among Ashkenazi Jews (16) and patients of Spanish ancestry (17).

Founder BRCA1 and BRCA2 mutations have also been found in several European populations in Austria, Slovenia, Italy, France, Spain, Portugal, Belgium, the Netherlands Germany, the Czech Republic, Slovakia, Hungary, Greece, Cyprus, Denmark, Sweden, Norway, Finland, Iceland, the United Kingdom, Ireland, Poland, Latvia, Lithuania, Estonia, Belarus, and Russia (18).

In Saudi Arabian women, BC is ranked first among all cancers, accounting for $27 \%$ of all newly diagnosed malignancies. While the majority of $\mathrm{BC}$ cases are sporadic, familial susceptibility to BC constitutes $25 \%$ of all cases (16).

Although the population in Saudi Arabia is largely homogeneous and consanguinity is very common, especially in the central, eastern, and southern regions of the country, the prevalence of BRCA1 and BRCA2 mutations and the characteristics of $\mathrm{BC}$ have not been extensively studied. Available data are conflicting and inconclusive, as they are based on retrospective analyses from small heterogeneous groups of Saudi and non-Saudi patients (19-24).

In this paper, we present a snapshot of the $B R C A$ studies that have been conducted in Arab countries in the Middle East. The $B R C A$ studies examined included those involving both BRCA1 and BRCA2. Table 1 shows the summary of studies included in this paper.

Six countries with varying incidence rates and types of $B R C A$ mutations were included: Saudi Arabia, Lebanon, Jordan, Qatar, Egypt, and Syria. The sample sizes ranged between 50 and 800 patients and the mean age at diagnosis ranged from 22 to 75 years. The type of testing employed varied and included multiple techniques. Mutation types were mostly deleterious. 
Table $1 B R C A$ mutations among breast and/or ovarian cancer patients in Arab countries

\begin{tabular}{lcccccc}
\hline Author & Year & Country & $\begin{array}{c}\text { Sample } \\
\text { size }\end{array}$ & $\begin{array}{c}\text { Age at diagnosis } \\
\text { (range or mean) }\end{array}$ & Test type & Mutation type \\
\hline Bu & 2016 & Saudi Arabia & 818 & 41.9 & PCR, CS/SS4, and TCS & Deleterious \\
El Saghir & 2015 & Lebanon & 250 & 40.8 & MLPA & Deleterious, VUS \\
Abdel-Razeq & 2018 & Jordan & 100 & $22-75$ & BART & Deleterious, suspected-deleterious \\
Bujassoum & 2017 & Qatar & 82 & $<50$ & MLPA & Deleterious \\
Jalkh & 2012 & Lebanon & 72 & 41 & Fluorescent DS & Deleterious, VUS \\
Abulkhair & 2018 & Saudi Arabia & 310 & - & PCR & Deleterious \\
Ibrahim & 2010 & Egypt & 60 & 43.5 & SSCP, HAC & Deleterious \\
Khalil & 2018 & Syria & 50 & 36 & PCR & Deleterious \\
\hline
\end{tabular}

BART, comprehensive BRACAnalysis and BRACAnalysis Rearrangement Test; PCR, polymerase chain reaction; CS, capture sequencing; SS, sanger sequencing; TCS, targeted capture sequencing; MLPA, multiple ligation-dependent probe amplification; SSCP, single-strand conformation polymorphism assay; HAC, heteroduplex assay confirmation; DS, direct sequencing; VUS, variants of uncertain significance.

There was a variability in the prevalence of $B R C A$ mutations in patients at high risk of having hereditary BC between $5.6 \%$ to $20 \%$ between different countries of the Arab world $(11,19,25,26)$. These differences might be explained by either biological differences in $B R C A$ gene prevalence (27) or differences in the age at onset in the study population $(28,29)$. Studies have also suggested that there is a variation of $B R C A$ prevalence among different ethnicities (16) while others found that the prevalence of these mutations is the same across different ethnicities (13). Family history of breast or ovarian cancer emerged as a significantly strong predictor for $B R C A$ gene mutations (30).

\section{Conclusions}

Understanding population-specific $B R C A$ gene distributions is critical, as this knowledge can be helpful in devising appropriate risk-assessment strategies to reduce the risk of cancer emergence and developing cost-effective strategies for genetic testing for BRCA mutations (24).

High-quality large-sample studies are necessary to better understand and recognize the impact of $B R C A$ gene mutations and their role in breast and ovarian cancer incidence, risk and prognosis, surveillance, management, and outcome in this part of the world where cancer incidence is steadily increasing.

\section{Acknowledgments}

The authors would like to thank Ms. Sheryl Ann Abdukahil and Ms. Donabel Bigtas-Castro for their outstanding editorial support.

Funding: None.

\section{Footnote}

Provenance and Peer Review: This article was commissioned by the Guest Editor (Shaheenah Dawood) for the series "Targeting the DNA Damaging Pathway: PARPi and Beyond" published in Chinese Clinical Oncology. The article has undergone external peer review.

Conflicts of Interest: Both authors have completed the ICMJE uniform disclosure form (available at http://dx.doi. org/10.21037/cco-19-204). The series "Targeting the DNA Damaging Pathway: PARPi and Beyond" was commissioned by the editorial office without any funding or sponsorship. The authors have no other conflicts of interest to declare.

Ethical Statement: The authors are accountable for all aspects of the work in ensuring that questions related to the accuracy or integrity of any part of the work are appropriately investigated and resolved.

Open Access Statement: This is an Open Access article distributed in accordance with the Creative Commons Attribution-NonCommercial-NoDerivs 4.0 International License (CC BY-NC-ND 4.0), which permits the noncommercial replication and distribution of the article with the strict proviso that no changes or edits are made and the 
original work is properly cited (including links to both the formal publication through the relevant DOI and the license). See: https://creativecommons.org/licenses/by-nc-nd/4.0/.

\section{References}

1. Bray F, Ferlay J, Soerjomataram I, et al. Global cancer statistics 2018: GLOBOCAN estimates of incidence and mortality worldwide for 36 cancers in 185 countries. CA Cancer J Clin 2018;68:394-424.

2. Larsen MJ, Thomassen M, Gerdes AM, et al. Hereditary breast cancer: clinical, pathological and molecular characteristics. Breast Cancer (Auckl) 2014;8:145-55.

3. Toss A, Tomasello C, Razzaboni E, et al. Hereditary ovarian cancer: not only BRCA 1 and 2 genes. Biomed Res Int 2015;2015:341723.

4. Moyer VA; U.S. Preventive Services Task Force. Risk assessment, genetic counseling, and genetic testing for BRCA-related cancer in women: U.S. Preventive Services Task Force recommendation statement. Ann Intern Med 2014;160:271-81.

5. Brown R, Kerr K, Haoudi A, et al. Tackling cancer burden in the Middle East: Qatar as an example. Lancet Oncol 2012;13:e501-8.

6. Saint-Germain MA, Longman AJ. Breast cancer screening among older Hispanic women: knowledge, attitudes, and practices. Health Educ Q 1993;20:539-53.

7. Al-Saad S, Al-Shinnawi H, Mahmood Shamsi N. Risk factors of breast cancer in Bahrain. Bahrain Medical Bulletin 2009;31:1-11.

8. Miller AB. Screening for breast cancer in the Eastern Mediterranean Region. East Mediterr Health J 2010;16:1022-4.

9. El Saghir NS, Khalil MK, Eid T, et al. Trends in epidemiology and management of breast cancer in developing Arab countries: a literature and registry analysis. Int J Surg 2007;5:225-33.

10. El Saghir N, Kreidieh F, El-Baba S, et al. Management of locally advanced and metastatic breast cancer: guidelines, infrastructures and low resource settings. Future Medicine 2016;5:69-77.

11. Laraqui A, Uhrhammer N, Lahlou-Amine I, et al. Mutation screening of the BRCA1 gene in early onset and familial breast/ovarian cancer in Moroccan population. Int J Med Sci 2013;10:60-7.

12. Arpino G, Pensabene M, Condello C, et al. Tumor characteristics and prognosis in familial breast cancer. BMC Cancer 2016;16:924.
13. Hall MJ, Reid JE, Burbidge LA, et al. BRCA1 and BRCA2 mutations in women of different ethnicities undergoing testing for hereditary breast-ovarian cancer. Cancer 2009;115:2222-33.

14. Kurian AW. BRCA1 and BRCA2 mutations across race and ethnicity: distribution and clinical implications. Curr Opin Obstet Gynecol 2010;22:72-8.

15. Kim H, Choi DH. Distribution of BRCA1 and BRCA2 mutations in Asian patients with breast cancer. J Breast Cancer 2013;16:357-65.

16. Balmaña J, Díez O, Rubio IT, et al. BRCA in breast cancer: ESMO Clinical Practice Guidelines. Ann Oncol 2011;22 Suppl 6:vi31-4.

17. Fackenthal JD, Olopade OI. Breast cancer risk associated with BRCA1 and BRCA2 in diverse populations. Nat Rev Cancer 2007;7:937-48.

18. Janavičius R. Founder BRCA1/2 mutations in the Europe: implications for hereditary breast-ovarian cancer prevention and control. EPMA J 2010;1:397-412.

19. El-Harith el-HA, Abdel-Hadi MS, Steinmann D, et al. BRCA1 and BRCA2 mutations in breast cancer patients from Saudi Arabia. Saudi Med J 2002;23:700-4.

20. Alshatwi AA, Shaf G, Hasan TN, et al. Single nucleotide polymorphisms in the $\mathrm{p} 21$ and bcl 2 cancer susceptibility genes and breast cancer risk in Saudi Arabia. Asian Pac J Cancer Prev 2011;12:2607-10.

21. Al-Moghrabi N, Al-Qasem AJ, Aboussekhra A. Methylation-related mutations in the BRCA1 promoter in peripheral blood cells from cancer-free women. Int J Oncol 2011;39:129-35.

22. Alanazi M, Pathan AA, Abduljaleel Z, et al. Association between PARP-1 V762A polymorphism and breast cancer susceptibility in Saudi population. PLoS One 2013;8:e85541.

23. Hasan TN, Shafi G, Syed NA, et al. Lack of association of BRCA1 and BRCA2 variants with breast cancer in an ethnic population of Saudi Arabia, an emerging high-risk area. Asian Pac J Cancer Prev 2013;14:5671-4.

24. Bu R, Siraj AK, Al-Obaisi KA, et al. Identification of novel BRCA founder mutations in Middle Eastern breast cancer patients using capture and Sanger sequencing analysis. Int J Cancer 2016;139:1091-7.

25. Farra C, Dagher C, Badra R, et al. BRCA mutation screening and patterns among high-risk Lebanese subjects. Hered Cancer Clin Pract 2019;17:4.

26. El Saghir NS, Zgheib NK, Assi HA, et al. BRCA1 and BRCA2 mutations in ethnic Lebanese Arab women with high hereditary risk breast cancer. Oncologist 
Page 4 of 4

2015;20:357-64.

27. Uhrhammer N, Abdelouahab A, Lafarge L, et al. BRCA1 mutations in Algerian breast cancer patients: high frequency in young, sporadic cases. Int J Med Sci 2008;5:197-202.

28. Abdel-Razeq H, Al-Omari A, Zahran F, et al. Germline BRCA1/BRCA2 mutations among high risk breast cancer
Abulkhair and El Saghir. BRCA: snapshot of the Middle East

patients in Jordan. BMC Cancer 2018;18:152.

29. Abulkhair O, Al Balwi M, Makram O, et al. Prevalence of BRCA1 and BRCA2 mutations among high-risk Saudi patients with breast cancer. J Glob Oncol 2018;4:1-9.

30. Neuhausen SL. Ethnic differences in cancer risk resulting from genetic variation. Cancer 1999;86:2575-82.
Cite this article as: Abulkhair O, El Saghir NS. BReast CAncer gene (BRCA): snapshot of the Middle East. Chin Clin Oncol 2021;10(5):51. doi: 10.21037/cco-19-204 